\title{
DADOS SOBRE AS RELAÇÕES ENTRE CINEMA E LITERATURA NO CINEMA NOVO BRASILEIRO
}

\author{
Víctor $\mathrm{Amar}^{1}$
}

\begin{abstract}
Resumo: Neste artigo a ideia principal é estabelecer um esquema comparativo abordando as relações entre o cinema e a literatura, com destaque para o cinema novo brasileiro. O mote principal do trabalho leva-nos a relacionar o romance e o cinema, mas nossa intenção é estabelecer um cômputo de relações entre o cinema e a literatura de cordel, o teatro e a música/poesia. Quer dizer, nosso interesse é abordar dados que tornam possíveis as relações entre a literatura e o cinema novo brasileiro. Um documento escrito com rigor busca sinais documentais da época em consonância com outros mais atuais.
\end{abstract}

Palavras-Chave: Cinema; Literatura; Relações cinema-literatura; Criação cinematográfica-literária.

Resumen: En este artículo la idea principal es la de establecer un esquema comparativo entre las relaciones entre el cine y la literatura con el cinema novo brasileño. Tal vez, el motivo principal nos lleva a atender la novela y el cine y la literatura de cordel, el teatro, la propia música/poesía. Es decir, nuestro interés está en mostrar, no demostrar, ya que el lector/espectador debe continuar su reconstrucción de los datos que hacen posible las relaciones entre cine y literatura con el cinema novo brasileiro. Un documento escrito con rigor y atendiendo a las señales documentales de la época con otros más actuales.

Palabras Clave: Cine; Literatura; Relaciones cine-literatura; Creación cinematográfica-literaria.

\section{GENERALIDADES INICIAIS}

Sem dúvidas os cinemanovistas formavam um grupo de jovens com um grande nível intelectual. As reuniões que tinham não eram só para falar de cinema, teorias e questões estéticas, mas também, de política e dos desejos duma turma comprometida em transformar sua realidade. Tam-

1 Departamento de Didática, Faculdade de Educação da Universidade de Cádiz, Espanha; autor de El cine nuevo brasileño 1954-1974 (1993); Editor de Hachetetepé "http" - Revista Científica de Educación y Comunicación, disponível em: www.grupoeducom.com. Endereço eletrônico: victor.amar@uca.es. 
bém era motivo para comentar as tendências musicais e ter um maior conhecimento da literatura, não só brasileira como também internacional. Todos tinham uma grande sensibilidade pelos romances, por ver as últimas produções do neorrealismo italiano ou da nouvelle vague francesa. As reuniões se davam no Rio de Janeiro, seja nos bares de Copacabana ou no Flamengo; na casa particular de Luis Fernando Goulart, grande amigo dos jovens cineastas Arnaldo Jabor e Carlos Diegues (de quem terminou sendo assistente de produção) e, igualmente, nos encontros semanais que se mantinham na cinemateca do Museu da Arte Moderna (MAM) da capital carioca.

Estamos ante um coletivo de amigos e colegas que tinham como finalidade a transformação do cinema para logo mudar o pensamento do povo brasileiro. A ideia do Mauro de Alencar de um cinema "educativo, realista e funcional", já foi apresentada no I Congresso Nacional de Cinema Brasileiro no Rio de Janeiro entre os dias 22 e 28 de setembro de 1952 e estava na linha defendida pelo cineasta cubano Julio Espinosa sobre "Um cinema imperfeito":

El cine imperfecto es una respuesta. Pero también es una pregunta que irá encontrando sus respuestas en el propio desarrollo.

El cine imperfecto puede ser divertido. Divertido para el cineasta y para su nuevo interlocutor. Los que no luchan al margen de la vida sino dentro. La lucha es vida y viceversa. El cine imperfecto no es exhibicionista en el doble sentido de la palabra. No lo es en el sentido narcisista; ni lo es en el sentido mercantil.

Al cine imperfecto no le interesa más la calidad ni la técnica.

Al cine imperfecto no le interesa más un gusto determinado y mucho menos el "bueno gusto".

El cine imperfecto no puede olvidar que su objetivo esencial es el de desaparecer como nuevo poética (ESPINOSA, 1976, p. 30-34).

E vinha a coincidir com os dados apresentados pelo grande crítico cinematográfico Emilio Sales Gomes (1960) que, na I Convenção Nacional da Crítica Cinematográfica celebrada em São Paulo de 12 a 15 de novembro de 1960, sustentava ideias muito parecidas à colonização audiovisual e dependência do cinema brasileiro. Assim, em sua conferência intitulada "Uma situação colonial?", o próprio crítico paulista fazia alusão à situação do cinema nacional, seu subdesenvolvimento e alienação.

O denominador comum de todas as atividades relacionadas com o cinema é, em nosso país, a mediocridade. A indústria, as cinematecas, o comércio, os clubes de cinema, a crítica, a legislação, os quadros técnicos e artísticos, o público [...], apresentam a marca cruel do subdesenvolvimento. A situação 
de colonizados implica em crescente alienação e no depauperamento do estímulo para empreendimentos criadores (SALES GOMES, 1968).

Contudo, a situação de mal-estar com a cultura em geral era evidente, porém a sensibilidade dos cinemanovistas quebrava esta iniciativa e vinculavam-se com as carências culturais do país. E tudo amparado pela política do Centro Popular de Cultura (CPC) da União Nacional de Estudantes (UNE) e pelo Institutos Superior de Estudos Brasileiros (ISEB).

\section{ALGUNS DADOS SOBRE AS RELAÇõES ROMANCE-CINEMA}

Seria muito complicado elencar títulos e diretores de cinema que mexeram com a literatura. Neste caso, nossa proposta passa por dar um repasso pelas relações existentes e, sobretudo, abrir um território para refletir sobre as ligações entre o romance e o cinema novo. Neste sentido, tomamos dois grandes grupos: a) romances de Graciliano Ramos e b) romances de outros autores.

Em primeiro lugar, um filme de grande sucesso foi Vidas secas (1963), dirigido por Nelson Pereira dos Santos, com um respeito grande à obra literária do nordestino Graciliano Ramos. Um filme bem feito, que deixa aberta a possibilidade para que o espectador/leitor possa olhar para o lado de fora do campo da representação e imaginar um merecido mundo melhor para as pessoas que vivem e sofrem no sertão nordestino.

No obstante, existe un matiz que las diferencia, si en el libro el propósito del escritor fue más psicológico, en el film la intención es más social; da la impresión de encontrarnos ante un documento de corte sociológico que narra la vida inhumana de una familia de nordestinos. Aunque esto no significa que el director no haya sido fiel a la novela de Ramos, respetando el texto original, situaciones y llevando a cabo un notable esfuerzo de síntesis (AMAR, 2000).

A literatura realista do nordestino Graciliano Ramos, concretamente o romance Vidas secas, é um bom exercício de adaptação. O respeito ao texto passa por poucas modificações e, talvez, chama à atenção a criação da personagem do companheiro da cadeia que no livro não existe. Um exemplo de síntese gravado nas terras do sertão alagoano (Palmeiras dos Índios), só devemos fazer uma distinção entre livro e filme; o livro é um grande estudo psicológico dos habitantes do nordeste brasileiro, aliás o filme tem uma maior perspectiva social, olhando e mostrando a vida inu- 
mana que vivem os sertanejos e a dureza do meio natural: a seca e a monotonia de suas vidas.

No caso da adaptação, houve um respeito absoluto [...]. Meu trabalho somente poderia ser o de respeito completo à forma e às idéias do autor do livro. Evidentemente que meu "approach" foi espontâneo, pois me empenhei em ilustrar fielmente a obra com toda uma suma de conhecimentos daquela realidade (MONTEIRO, 1970, p. 9).

Um filme de esquerda, inspirado num romance que poderia ser interpretado como revolucionário, ganhou o reconhecimento em festivais como os de Cannes, Varsóvia ou Gênova. E teve na ambientação um grande aliado, assim como na fotografia do cearense Luiz Carlos Barreto. Um filme itinerante que nos possibilita conhecer o sofrimento e as vontades e pretensões de uma família do sertão.

Em segundo lugar, continuando com o autor Graciliano Ramos, o romance a ser tratado é São Bernardo. Uma nova adaptação fiel onde a moral, algo marxista, graciliana invade a tela. Em 110 minutos o diretor Leon Hirzsman faz um resumo do romance homônimo e de novo o estado de Alagoas será o cenário natural e inspirativo. Exibida em 1973, poderíamos fazer várias interpretações; seja atendendo aos comportamentos machistas do heroi (Paulo Honório, no filme Othon Bastos); ou analisando o espírito lutador de sua mulher (Isabel Ribeiro, no papel de Madalena), onde o autor aproveita para dar a conhecer sua visão do social, da política, e das ideias socialistas. Um filme que desperta interesses e continua sendo um referencial e um modelo de intenções para a esquerda. O romance é atemporal e mantém uma temática universal: o ciúme e a necessidade de mudar.

O filme situa-se em anos muito duros de grande controle da censura. A vontade de falar ao povo brasileiro era uma necessidade dos diretores cinemanovistas. $\mathrm{O}$ controle do estado era muito pesado e os cineastas necessitavam de estratégias para superá-la.

De 1964 para cá, a censura federal se tornou mais drástica. Não há um só filme brasileiro importante que não tinha enfrentado problemas criados pelo Serviço de Censura do Departamento Federal de Segurança Pública (EDITORIAL, 1968).

O filme ganhou diferentes prêmios, seja em Cannes, Pésaro ou na França, seja também no Brasil, onde a Confederação Nacional de Bispos Brasileiros (CNBB) recomendou o filme, já que era de grande qualidade e sua temática contribuía para o progresso espiritual e desenvolvia os valores humanos. 
Gostaríamos de continuar com esta reflexão falando de vários filmes que pertencem ao patrimônio do cinema novo e da literatura brasileira. Por exemplo, um romance histórico como Ganga Zumba, o rei dos Palmares, escrito por João Felício dos Santos e que foi levado ao cinema em 1963 por Carlos Diegues. Um estudo audiovisual dos comportamentos humanos em cativeiro e em liberdade segundo fatos históricos que inspirou o romance e que são interpretados no cinema como um canto à liberdade nos séculos XVII e XVIII. Assim também podemos falar do romance de José Lins de Rego, que inspirou o filme Menino de engenho (1965), dirigido por Walter Lima Jr., onde o cineasta atualiza e reescreve o argumento apresentado um nordeste sem cangaceiros nem lutas nem "cabras"; agora a história centra seu foco nos impedimentos para encontrar o progresso e a decadência dum Brasil fechado ao século XX. Imagens visuais onde figura o cavalo frente ao carro, o bagaço frente à eletricidade, um menino frente ao futuro.

Antes de finalizar esta proposição sobre alguns dados sobre as relações cinema-romance, resta mencionar dois bons exemplos; 1) o caso de Macunaíma, escrito por Mário de Andrade em 1928, dentro da linha modernista, e dirigido em 1969 por Joaquim Pedro de Andrade. Certamente fiel ao texto, atualizado à realidade brasileira, o filme é uma convite pseudo-cômico para se acompanhar a situação dum grande país chamado Brasil, fruto de sua história e de suas circunstâncias e contradições. No que pese a censura, o filme foi um êxito de público e supõe um bom exemplo de como o cinema brasileiro na época da ditadura poderia cativar seu público e lotar as salas de projeções. Com um grande número de prêmios e reconhecimentos nacionais e internacionais, o cinema novo foi acabando pouco a pouco em tempos da ditadura.

Igualmente, o romance de Lúcio Cardoso Crônica da casa assassinada foi o motivo inspirativo para que, em 1971, Paulo César Saraceni o levasse ao cinema. Uma análise em três níveis: a) econômico, segundo a decadência e involução do Brasil; b) moral, graças à visão pessoal dos personagens (heterossexual e homossexual); c) social, olhando a uma possível ruptura entre o velho e o futuro.

Não temos esquecido um filme chamado Capitu, baseado no romance de Machado de Assis intitulado Dom Casmurro, dirigido por Paulo César Saraceni em 1969. O filme contou com uma equipe muito experiente; por exemplo, na adaptação esteve implicado o crítico e professor Emilio Salles Gomes. Um filme que tem três partes sobre a adolescência de Bentinho, o casamento, a separação e sua solidão final. Um filme metáfora repleto de 
estudos psicológicos das personagens que analisa a ruina de um homem corroído pelo ciúme da sua mulher, Capitu.

Machado não dialoga. [...] mesmo fala em seus romances [...]. Quem fala por elas, que as revela,é o romancista. Daí as dificuldades de colocar diálogos na boca das personagens machadianas (FAGUNDES, 1968).

Também não poderíamos concluir este texto sem analisar o filme Fome de amor (1968), dirigido por Nelson Pereira dos Santos, que esteve inspirado livremente no romance História para se ouvir de noite, de GuiIherme de Figueiredo. $\mathrm{O}$ romancista não gostou da adaptação e recusou o filme.

Meu roteiro foi posto de lado [...] um diálogo que jamais nasceria da minha modesta pena [...]. De fato, é imperdoável que eu houvesse inspirado aquilo (FIGUEREIDO, 1968).

Um filme enigmático, com grandes doses de análise política e social, no qual se evidencia um levantamento contra a ordem estabelecida. Um personagem principal que é cego, mudo e surdo. Uma contradição posto que não pode ver, discutir ou escutar. Uma história isolada, às vezes complicada onde no fundo do argumento está o tráfico internacional de armas. Algo muito simbólico, dificilmente interpretável por um público normal. Um filme complicado que fez com que o diretor retornasse às aulas universitárias na Universidade Federal Fluminense (Rio de Janeiro) para encarregar-se da docência no setor das artes cinematográficas.

\section{OUTROS MOTIVOS INSPIRADORES}

Mas nem tudo no cinema novo foi inspirado no roamance; também temos casos de relação literária-cinematográfica, por exemplo, com o teatro. Na época gozavam dum grande sucesso as peças teatrais de Nelson Rodrigues e isso faz com que o cineasta carioca Leon Hirszman tomasse a peça $A$ falecida (1965), que faz um estudo do jeito cru de viver o dia a dia na cidade do Rio de Janeiro. O texto literário foi escrito em 1956 e filmado em 1965 no Rio de Janeiro e contou com os ajustes de diálogos feitos pelo próprio Nelson Rodrigues e, aliás, ele fez a produção junto a seu filho Jofre. O filme é um estudo racional sobre a miséria carioca da classe média. Não só uma miséria econômica, senão também no âmbito da vida mesma que pode ser traduzida em desesperação e falta de perspectiva para continuar lutando com dignidade. A situação se complica com a alienação religiosa e 106 Número temático: literatura e cinema. A Cor das Letras - UEFS, n. 11, 2010 
com o esporte (futebol). O filme teve vários prêmios e reconhecimentos. Sobretudo, cabe assinalar a Gaivota de Prata no I Festival Internacional do Rio em 1965 e o escândalo que foi o fato de não representar o Brasil no Festival de Veneza (Itália). Não obstante, Hirszman já teve uma vinculação com o teatro de Nelson Rodrigues antes, quer dizer, em 1962 com a peça $O$ boca de ouro, onde faz uma análise da vida do bicheiro carioca que com uma mão matava e com a outra dava dinheiro. Não é um filme sobre a apologia do crime e, possivelmente, tenha muito de denúncia e análise social. Um estudo sobre a personalidade e a razão de ser do rei do bicho no morro da Madureira, mas também um acerto do cinema do sul num período onde o cinema novo estava dominado pelos nordestinos e esta zona do Brasil era motivo inspirativo de muitas películas, seja no caso do Glauber Rocha, seja no do Nelson Pereira dos Santos (que na época estava no nordeste gravando Vidas Secas), etc.

Outro motivo inspirador do nordeste brasileiro é um gênero literário que tem pouca elaboração no cinema. Estamos falando da literatura de cordel. Esta literatura rimada onde a palavra e o desenho estavam muito unidos teve um grande desenvolvimento no nordeste. Versos curtos recitados de forma melodiosa acompanhados de violão. Certamente, o filme Deus e o diabo na terra do sol (1964), dirigido por Glauber Rocha, introduz elementos da literatura de cordel como a temática narrada que tem muito da vida cotidiana misturada com assuntos religiosos, lendas e episódios da própria história, além de personagem ligados à terra e protagonistas das histórias narradas. Assim o argumento do filme poderia estar ligado a qualquer fato cotidiano do nordeste; agora bem, temos certeza que o personagem cego que narra a história faz as vezes de romanceiro que sem participar no desenvolvimento do argumento do filme é testemunho e com seu violão vai narrando o que o espectador precisa para compreender a história narrada com imagens sobre o cangaceiro Antônio das Mortes. Um western brasileiro carregado de alienação, religiosidade e violência. O próprio Glauber Rocha (1985, p. 279) dá uma ideia muito acertada do que significou o filme: "Uma guerra sem a cegueira de Deus e o Diabo. E para começar logo, eu, que já matei Sebastião, vou matar Corisco". Um filme, ao igual que a função do cego, que era divulgar uns fatos inspirados na tradição popular e nas personagens locais, dentro dum contexto de analfabetização e muito arraigados ao folclore nacional. Um jeito de educar, uma lição magistral de cinema e literatura; ou seja, de convivência entre o filme e a literatura de cordel. 
A relação cinema literatura, e vice-versa, está presente também em outros gêneros literários. Temos falado do romance, do teatro, da literatura de cordel e também faltaria dar alguns dados sobre a canção/poesia. Quer dizer, estamos falando da famosa "Garota de Ipanema", escrita pelo compositor carioca Antonio Carlos Jobim, inspirando-se no doce balanço das meninas duma cidade maravilhosa, onde tudo é uma bonita ficção nos bairros ricos da zona sul, onde os protagonistas vivem suas vidas em harmonia, longe da realidade de uma cidade em transformação. Um filme que tem seu motivo inspirativo na canção, que para nós está intimamente ligado à poesia, mais também tem sua história ligada ao cinema novo, pois Leon Hirszman conheceu o roteirista Eduardo Coutinho quando trabalhavam na adaptação da peça teatral $A$ falecida. Um filme que é musical mas está completamente cheio de poesia. Um longa metragem que fez o cinema novo e o povo brasileiro se olharem direito aos olhos. Um sucesso que teve poemas cantados pelo próprio Vinícius de Moraes, por exemplo, com o "Poema dos olhos da amada". Talvez, a primeira vez em que o cinema novo usa a cor num filme e a presença com grandes mestres da canção como Chico Buarque de Holanda, entre outros.

Agora, certamente inspirada no poema de Carlos Drummond de Andrade foi o filme homônimo de Joaquim Pedro de Andrade, intitulado $O$ padre e a moça (1966). O livro inspirativo do filme foi publicado em 1962 com o título geral de Lição de coisas. Uma película que teve graves problemas com a censura, seja a nível federal, que a proibiu para menores de 21 anos, o que quase condenava o filme a um público só adulto, o que provocou passeatas em Belo Horizontes e no Rio de Janeiro a favor da liberdade de criação e a intolerância cultural; seja também com a censura religiosa, onde a igreja católica, sobretudo o cardeal de São Paulo, organizou uma campanha contra o filme, já que, segundo a igreja católica, era desmoralizante. Para isso, escreveu uma carta ao chefe do departamento federal da segurança pública pedindo sua proibição e a ulterior intervenção no assunto. Para ter uma ideia das intenções da igreja católica, a Conferência Nacional de Bispos Brasileiros (CNBB) se expressava nos termos seguintes, segundo apreciação artística e moral:

No tema da fuga, visualizado nas andanças filmadas "ao Godard" estão nos melhores momentos do filme. Completamente ausentes a caracterização do sacerdote e um aprofundamento psicológico dos protagonistas. Pontos positivos são a ambientação autêntica e a atmosfera realista através de boa fotografia, não faltando momentos de poesia. 
A ausência do caráter sacerdotal do protagonista, certa descrição na cena da sedução (imposta pela censura) diminui as inconveniências e o chocante do caso. Adultos, em todo o sentido da palavra, poderão julgar o caso.

Adultos, com reservas (Serviço de Informação Cinematográfica da Central Católica de Cinema, 1966).

A própria oficina católica internacional do cinema não repara na metáfora visual que se presta a interpretações entre um Brasil atrasado, que aceita a relação entre um velho tutor, e a jovem, frente a um Brasil tolerante e moderno, que deveria aceitar a atração normal entre jovens, aliás, um deles seja padre. O poema e o filme fazem um acertamento à intolerância e aos prejuízos sociais irracionais. Um filme que está baseado no poema, com um trabalho no roteiro importante do mesmo diretor e com uma importância sobressalente com música de Carlos Lira ao som da bossa nova. Uma lição de coabitação entre a poesia e o cinema, tendo que ceder às vezes ao texto poético para ser uma metáfora visual e, em outras ocasiões, ser reinterpretado à presença grandiloquente da imagem como um pretexto interpretativo. Infelizmente, o filme foi um fracasso na bilheteria.

Temos que finalizar esta incursão nas relações entre literatura e cinema novo fazendo uma alusão ao conto. Estamos convencidos que o leitor/espectador tem na cabeça títulos, mas nós só queremos oferecer um que foi muito importante para compreender a última trama do cinema novo brasileiro. Trata-se do filme Azyllo muito louco (1970), dirigido por Nelson Pereira dos Santos, baseado no conto "O alienista", de Machado de Assis, publicado em 1882. Novamente é Nelson Pereira dos Santos o encarregado de fazer o roteiro e a direção do filme que é apresentado em 1970. Um claro exemplo do tropicalismo cinematográfico numa etapa onde o cinema estava sendo questionado pelos políticos da época. Um exercício onde as preocupações do padre são muito parecidas à da cidadania brasileira da ditadura. Quer dizer, mais que sua saúde espiritual está a saúde mental. A primeira vez que o Nelson Pereira dos Santos usa imagem em cores em um filme que não foi muito compreendido pelo grande público, mas sim pela crítica e foi, igualmente, premiado no Festival de Cannes em 1970, onde recebeu o prêmio Luis Buñuel outorgado pela crítica espanhola.

O último exemplo desta ampla epígrafe seria o filme Os inconfidentes (1972), de Joaquim Pedro de Andrade. Uma análise das coisas não bem feitas ou que nunca chegaram a ser feitas... Inspirado livremente nos "Autos da devassa" e em "O romanceiro da inconfidência", de Cecília Meireles, o filme é uma reflexão sobre a luta contra os poderes tirânicos em clara 
alusão a estes textos históricos reinterpretados numa época onde o Brasil está sob o jugo da ditadura militar.

El argumento fue realizado tras investigaciones, llevadas a cabo por el proprio director y Eduardo Escorel, basadas en los "Autos da Devessa" de La Inconfidência Minera, y en los poemas de los inconfidentes de Cláudio Manoel da Costa, Tomas Antônio Gonzaga, Alverenga Peixoto, y de la poetisa Cecília Meireles, com sua obra "Romanceiro da Inconfidência" (AMAR, 1993, p. 189).

Como pôr em questionamento as palavras do pai da pátria brasileira, o Tiradentes? Talvez esta fosse a única maneira de contornar a censura. Uma mistura de história, poesia, romanceiro e muita imaginação, em tempos onde o cinema novo era outra coisa, e os jovens cineastas haviam crescido, não só em idade senão também em estética e sensibilidade cinematográfica.

\section{ALgUMAS IDEIAS PARA FINALIZAR}

A ideia que temos seguido na exposição deste artigo tem sido a de não fazer um possível catálogo de relações entre a literatura e o cinema novo. Temos buscado brincar e convidar o espectador/leitor a fazer e refazer uma interpretação do acontecido entre as letras e as imagens. É certo que o cinema novo começou buscando inspiração na realidade (neorrealismo italiano) e depois optou pelo cinema de autor (nouvelle vague francesa), porém compreendeu que, para tocar mais de perto o povo brasileiro, também teve que olhar pela literatura deste país, sendo coerente com a ideia do projeto inicial de pertença à cultura do Brasil.

É muito complicado finalizar uma temática tão ricamente nutrida de histórias e relações literário-cinematográficas. Um momento da história do cinema cheio de compromissos literários que tinha uma clara intenção: mostrar ao grande público brasileiro as riquezas de sua literatura. Porém, cada vez que um cineasta pegava um romance, um conto, uma poesia, etc., fazia um claro exercício maior que de adaptação, o que tentava era colocar um pouco mais perto uma parte importante do patrimônio por meio do cinematográfico.

Um cinema generoso que tinha motivos inspirativos na literatura seja realista, de corte histórico, seja modernista... mas sempre com a intenção de ser fiel aos conteúdos literários. Às vezes, era impossível a capacidade de reinvenção do cineasta devido a obrigações impostas pelos complicados 110 Número temático: literatura e cinema. A Cor das Letras - UEFS, n. 11, 2010 
momentos históricos (ditadura de Castelo Branco ou Costa e Silva) em que se desenvolveu o cinema novo brasileiro. Também temos casos de obras literárias que foram motivo apenas de inspiração e em poucos casos a adaptação foi livre a partir dos textos literários. Assim, o rigor e o respeito à obra literária será quase uma norma, não escrita, mais temos que ter presente que as relações entre literatura e cinema estão inspiradas em reciprocidade e, sobretudo, em reconhecer que são meios diferentes: a literatura tem como referente a palavra impressa, onde a capacidade de invenção do leitor é muito importante, aliás, no cinema a ação está dada pela palavra transmitida oralmente e, sobretudo, pela visão e, mesmo assim, a imaginação do espectador também é muito importante, já que não só intervém no relato fílmico - o que os olhos do público assistem -, é importante o que está fora do plano e temos que recompor. Em ambos os casos, a reinvenção da obra não só está na caneta ou no roteiro-montagem do cineasta, mas também nas capacidades desenvolvidas pelos leitores ou espectadores.

Neste caso, temos muitos bons exemplos de adaptação literáriascinematográficas e sempre dando uma importante abertura para que os interessados possam dar intenções interpretativas aos resultados. $\mathrm{E}$, igualmente, a literatura foi utilizada na maioria dos casos como um referente inquestionável onde a censura teria que fazer um exercício proibitivo, não só na parte literária, senão também na parte cinematográfica e, às vezes, foram utilizados os mitos e as personagens literárias (de muito arraigo popular ou membros fundadores da pátria brasileira) para salvar-se dos próprios órgãos censores. Estamos ante um enorme exercício de representação e interpretação literário-cinematográfica.

As relações, de acordo com os dados, entre literatura e cinema ou cinema e literatura, grosso modo, podemos dizer que são muitas boas. As relações literrae-imago são uma lição de coexistência e de complemento. Seria impossível entender o cinema novo brasileiro sem a presença da literatura e, talvez, seria muito complicada achar uma obra cinematográfica do período estudado completamente livre de relações da herança da literatura, inclusive sendo fruto dum argumento da imaginação dum cineasta. Quer dizer, os próprios cinemanovistas estavam e eram conscientes da presença da literatura dentro e fora de suas manifestações fílmicas. A maioria dos cinemanovistas eram conhecedores da literatura e da tradição literária do Brasil. 


\section{REFERÊNCIAS}

ALENCAR, Mauro de. Tese apresentada no I Congresso Nacional de Cinema Brasileiro. 22-28 de setembro de 1952. Rio de Janeiro. Sem páginas.

AMAR, Víctor Manuel Rodríguez. El cine nuevo brasileño 1954-1974. Madrid: Dykinson, 1993. AMAR, Víctor Manuel Rodríguez. Graciliano Ramos en el cine brasileño: notas para la literatura y el cine. Revista Latina de Comunicación Social, n. 30. 2000. Disponível em: http://www.ull.es/ publicaciones/latina/aa2000qjn/95amar.html. Acesso em: 1 fev. 2011.

EDITORIAL. Contra a censura. Revista A parte, n. 2; publicado pelo TUSP, São Paulo, 1968.

ESPINOSA, Julio. Por um cine imperfecto. Madrid: Castellote, 1976.

FAGUNDES, Lígia. Capitu. O Estado de São Paulo. São Paulo, 28/4/1968.

FIGUEREIDO, Guilherme. Fome de Amor. O Jornal. Rio de Janeiro, 30/6/1968.

MONTEIRO, José Carlos. Nelson Pereira dos Santos: depoimentos. Filme Cultura, n. 16, 1970. ROCHA, Glauber. Roteiros do Terceyro mundo. Rio de Janeiro: Alhambra/Embrafilme, 1985.

SALES GOMES, Paulo Emilio. Conferência: Uma situação colonial?, na I Convenção Nacional da Crítica Cinematográfica. São Paulo, 12-20 de novembro de 1960.

SERVIÇO de Informação Cinematográfica da Central Católica de Cinema. Rio de Janeiro, 1966.

\section{Webgrafia}

Portal do cinema latinoamericano. Disponível em: http://www.cinelatinoamericano.org/.

Espaço para o cinema brasileiro. Disponível em: http://www.cinemabrasileiro.net/.

Página sobre o cinema brasileiro. Disponível em: http://www.cinemabrasil.org.br/site02 /index.html.

Cinemateca brasileira. Disponível em: http://www.cinemateca.gov.br/.

Wikipédia sobre cinema brasileiro. Disponível em: http://pt.wikipedia.org/wiki/Cinema_do_ Brasil. 